\title{
$\mathrm{RF}$ 마그네트론 스퍼터링법에 의한 SBN 박막의 분극특성
}

\begin{tabular}{|c|}
\hline 논 문 \\
\hline $60-6-15$ \\
\hline
\end{tabular}

\section{Polarization Characteristics of SBN Thin Film by RF Magnetron Sputtering}

\author{
김 진 사* \\ (Jin-Sa Kim)
}

\begin{abstract}
The SBN thin films were deposited on $\mathrm{Pt} / \mathrm{Ti} / \mathrm{SiO}_{2} / \mathrm{Si}$ and $\mathrm{p}$-type $\mathrm{Si}(100)$ substrate by rf magnetron sputtering method using $\mathrm{Sr}_{0.7} \mathrm{Bi}_{2.3} \mathrm{Nb}_{2} \mathrm{O}_{9}$ ceramic target. SBN thin films deposited were annealed at $600 \sim 800\left[{ }^{\circ} \mathrm{C}\right]$ by furnace in oxygen atmosphere during 40min. The polarization characteristics have been investigated to confirm the possibility of the SBN thin films for the application to destructive read out ferroelectric random access memory. The maximum remanent polarization and the coercive voltage are $0.6\left[\mu \mathrm{C} / \mathrm{cm}^{2}\right], 1.2[\mathrm{~V}]$ respectively at annealing temperature of $800\left[{ }^{\circ} \mathrm{C}\right]$. The leakage current density was the $2.57 \times 10^{-6}\left[\mathrm{~A} / \mathrm{cm}^{2}\right]$ at an applied voltage of $5[\mathrm{~V}]$ at annealing temperature of $650\left[{ }^{\circ} \mathrm{C}\right]$. Also, the fatigue characteristics of SBN thin films did not change up to $10^{8}$ switching cycles.
\end{abstract}

Key Words : Sputtering, Polarization, Coercive voltage, Leakage current, Fatigue

\section{1. 서 론}

최근 강유전체의 다양한 응용성 때문에 박막화를 시도하 는 연구가 활발히 진행되고 있다. 현재 DRAM이 고집적화 가 가능하고 동작 속도가 빠르며 기록가능 횟수에 거의 제 약이 없는 등 여러 가지 장점 때문에 가장 많이 사용되는 대표적인 메모리 소자로 알려져 있지만 데이터의 갱신을 하 기 위해 일정시간 간격으로 전압을 인가하여 주어야하는 휘 발성 메모리이다. 그래서 최근에는 전원의 공급이 없어도 데이터가 손상되지 않은 비휘발성 메모리로서 FRAM이 각 광을 받고 있으며, FRAM은 비휘발성 특성과 더불어 빠른 동작속도, 저전압 동작 및 $10^{12}$ 이상의 기록가능 횟수 등의 장점을 가지고 있는 것으로 알려져 있다.[1] 메모리 소자용 고유전율 물질로는 $\mathrm{SrTiO}_{3}(\mathrm{ST}), \mathrm{BaTiO}_{3}(\mathrm{BT}), \mathrm{PbTiO}_{3}(\mathrm{PT})$, $\mathrm{Ta}_{2} \mathrm{O}_{5}, \mathrm{BST}, \mathrm{PZT}$ 등이 활발히 연구되고 있다. 이러한 고유 전율 재료중에 FRAM용 유전체 박막재료로 가장 널리 알려 진 재료는 $\mathrm{PZT}$ 계 재료이며, $\mathrm{PZT}$ 박막은 유전율이 높고 항 전력이 작으며 잔류 분극량이 크고 높은 큐리온도 때문에 비휘발성 재료로 적합한 특성을 가지고 있으나 누설전류가 크고 절연파괴 전압이 낮으며 잔류분극이 방치시간 및 스윗 칭 횟수에 따라 감소하는 피로현상이 발생하는 단점을 가지 고 있다. 이러한 단점을 개선하기 위해 $\mathrm{RuO}_{2}, \mathrm{IrO}_{2}$ 와 같은 산화물 전극을 사용하여 피로현상을 개선시키려는 노력을 하였으나 이들 산화물 전극은 집적화의 복잡성을 증가시킨 다. 그래서 또 다른 대안으로 비스무스계 층상 페로브스카 이트 박막인 $\mathrm{SrBi}_{2} \mathrm{Nb}_{2} \mathrm{O}_{9}(\mathrm{SBN})$ 과 $\mathrm{SrBi}_{2} \mathrm{Ta}_{2} \mathrm{O}_{9}(\mathrm{SBT})$ 으로 이

\footnotetext{
* 정 회 원 : 조선이공대학 메카트로닉스과 교수

E-mail: kimjs@cst.ac.kr

접수일자 : 2011년 5월 6일

최종완료 : 2011년 5월 18일
}

러한 피로현상을 해결하려는 연구가 시도되고 있다.[2] SBN 과 SBT는 구조상 비스무스 산화물층이 분극반전이 발생하 는 층과 완충층 역할을 하는 $\mathrm{Bi}$ 산화물 층이 반복적으로 존 재하므로서 피로특성이 우수하다고 알려져 있으며, 동작전압 이 작고 고집적화에 유리한 특성을 가지고 있다. 한편 SBT 는 공정온도가 $800\left[{ }^{\circ} \mathrm{C}\right]$ 이상으로 기존의 반도체 라인을 이용 하기가 너무 높아 이보다는 결정화 온도가 낮은 $\mathrm{SBN}$ 이 차 세대 유전체 박막 재료로 많은 관심이 모아지고 있다.[3] 일 반적으로 $\mathrm{SBN}$ 박막을 제조하는 방법으로는 액상법인 졸-겔 법, $\mathrm{MOD}$ 법, $\mathrm{MOCVD}$, 스퍼터링법 등이 이용되고 있지만 저 온화 공정을 통해 강유전성을 지닌 $\mathrm{SBN}$ 박막을 제조하기가 어려워 여러가지 변화된 공정방법을 통해 $\mathrm{SBN}$ 박막 제조에 노력하고 있다.

따라서 본 연구에서는 $\mathrm{RF}$ 마그네트론 sputtering법을 이 용하여 $\mathrm{Pt} / \mathrm{Ti} / \mathrm{SiO}_{2} / \mathrm{Si}$ 기판 위에 $\mathrm{SBN}$ 박막을 증착한 후, 열 처리 온도에 따른 분극 특성에 대하여 고찰하고자 한다.

\section{2. 실 험}

본 실험에서는 $\mathrm{Sr}_{0.7} \mathrm{Bi}_{2.3} \mathrm{Nb}_{2} \mathrm{O}_{9}(\mathrm{SBN})$ 세라믹 타켓을 이용 하여 $\mathrm{RF}$ 마그네트론 스퍼터링법으로 $\mathrm{P}$-type $\mathrm{Pt} / \mathrm{Ti} / \mathrm{SiO}_{2}$ $/ \mathrm{Si}(100)$ 기판위에 기판온도 $300\left[{ }^{\circ} \mathrm{C}\right]$ 에서 60 분 동안 증착한 후, 전기로에서 $600 \sim 800\left[{ }^{\circ} \mathrm{C}\right]$ 로 40 분 동안 열처리하였다. 실 험에 사용된 기판의 사양은 $\mathrm{SiO}_{2}-3000[\AA], \mathrm{Ti}-100[\AA]$, $\mathrm{Pt}-1500[\AA]$ 등이다. 실리콘 웨이퍼는 $10 \times 10\left[\mathrm{~mm}^{2}\right]$ 으로 절단하 여 초음파 세척함으로써 표면에 잔류하는 불순물을 완전히 제거하였다. 상부전극(top electrode)은 스퍼터링법을 이용하 여 직경 $300[\mu \mathrm{m}]$ 로 백금 $(\mathrm{Pt})$ 을 $2000[\AA]$ 의 두께로 증착하여 사용하였다. 열처리한 $\mathrm{SBN}$ 박막의 $\mathrm{P}-\mathrm{V}$ 특성은 인가전압 \pm 10 [V]에서 TF-2000E(aixACCT Systems GmbH)를 이용하 여 측정하였다. 또한 열처리된 시편의 $\mathrm{I}-\mathrm{V}$ 특성은 인가전압 
士5[V]에서 6430SUB-FEMTOAMP Source Meter(Keithley) 를 사용하였고, 피로 특성은 피로 사이클 $10^{8}$ 까지 $\mathrm{TF}-2000 \mathrm{E}$ 를 사용하여 측정하였다.

\section{3. 결과 및 고찰}

그림 1은 $\mathrm{SBN}$ 박막의 열처리온도에 따른 $\mathrm{P}-\mathrm{V}$ 특성을 나타낸 것이다. 그림에서 볼 수 있는 것처럼 모든 박막에서 거의 선형적인 $\mathrm{P}-\mathrm{V}$ 특성을 나타내고 있다. 열처리온도가 증 가함에 따라 $\mathrm{P}-\mathrm{V}$ 곡선이 약간씩 발달된 모양을 보이고 있 으며, 특히 열처리온도 $750\left[{ }^{\circ} \mathrm{C}\right]$ 이상에서 잘 발달된 $\mathrm{P}-\mathrm{V}$ 특 성이 나타나고 있는데 이것은 전자현미경 사진에서 볼 수 있었던 것처럼 열처리온도 $750\left[{ }^{\circ} \mathrm{C}\right]$ 이상에서 입자가 크고 뚜 렷하게 성장되어 존재하기 때문이라 생각된다.[4] 또한 $\mathrm{P}-\mathrm{V}$ 특성 곡선이 양의 전압쪽으로 약간 이동됨을 알 수 있는데, 이는 내부 전기장이 상부전극 쪽으로 향하고 있음을 나타내 며 상부전극은 $\mathrm{dc}$ 스퍼터링법으로 증착되어 캐리어들이 전 극계면에 trap되어 영향을 미쳤을 것으로 사료된다.[5] 800 $\left[{ }^{\circ} \mathrm{C}\right]$ 에서 열처리한 $\mathrm{SBN}$ 박막의 잔류분극 값 및 항전압은 각각 $0.6\left[\mu \mathrm{C} / \mathrm{cm}^{2}\right], 1.2[\mathrm{~V}]$ 임을 알 수 있었다.

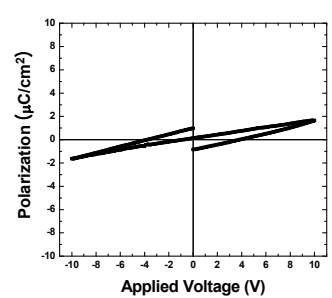

(a) $600\left[{ }^{\circ} \mathrm{C}\right]$

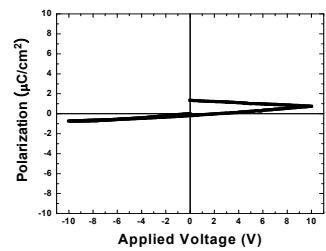

(c) $700\left[{ }^{\circ} \mathrm{C}\right]$

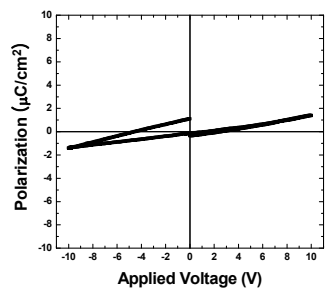

(b) $650\left[{ }^{\circ} \mathrm{C}\right]$

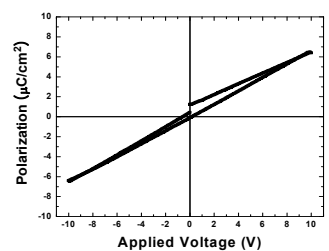

(d) $750\left[{ }^{\circ} \mathrm{C}\right]$

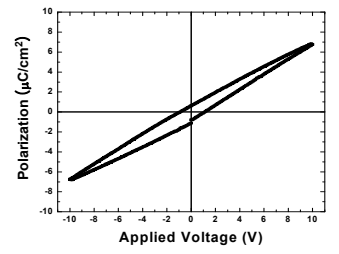

(e) $800\left[{ }^{\circ} \mathrm{C}\right]$

그림 1 열처리온도에 따른 SBN 박막의 $\mathrm{P}-\mathrm{V}$ 특성

Fig. $1 \mathrm{P}-\mathrm{V}$ characteristics of SBN thin films with annealing temperature

그림 2 는 열처리온도 $\left(600 \sim 800\left[{ }^{\circ} \mathrm{C}\right]\right)$ 에서 각각 열처리한 $\mathrm{SBN}$ 박막의 $\mathrm{I}-\mathrm{V}$ 특성을 나타내었다. 인가전압 5[V]에서 누 설전류 밀도는 열처리온도 $600\left[{ }^{\circ} \mathrm{C}\right]$ 에서 $650\left[{ }^{\circ} \mathrm{C}\right]$ 증가할 때는
$3.15 \times 10^{-6}\left[\mathrm{~A} / \mathrm{cm}^{2}\right]$ 에서 $2.57 \times 10^{-6}\left[\mathrm{~A} / \mathrm{cm}^{2}\right]$ 으로 약간 향상되었지만 열처리온도 $700\left[{ }^{\circ} \mathrm{C}\right]$ 이상에서는 더 나빠지다가 $800\left[{ }^{\circ} \mathrm{C}\right]$ 에서 절연 파괴되는 것을 확인할 수 있었다. 일반적으로 $\mathrm{MFM}$ 구조에서 누설전류 특성은 상부전극을 통해 박막내로 전하 주입 현상이 일어날 때 그 성능이 저하된다고 사료된다. 따 라서 박막 표면의 거칠기가 박막의 누설전류 특성에 영향을 준 것으로 생각된다.[6] 즉 본 연구에서 제작된 $\mathrm{SBN}$ 박막의 $\mathrm{AFM}$ 측정결과 열처리온도 $600\left[{ }^{\circ} \mathrm{C}\right]$ 에서 $650\left[{ }^{\circ} \mathrm{C}\right]$ 증가할 때 는 표면의 거칠기가 $7.7[\mathrm{~nm}]$ 에서 $0.42[\mathrm{~nm}]$ 로 감소하여 매 끄러운 표면을 나타내었지만 $700\left[{ }^{\circ} \mathrm{C}\right]$ 이상에서 표면 거칠기가 다시 상승하여 $800\left[{ }^{\circ} \mathrm{C}\right]$ 에서는 $24.06[\mathrm{~nm}]$ 으로 가장 크게 나타 났다. 이것은 입자가 과성장하여 $\mathrm{SBN}$ 박막 표면의 균일성 이 저하됨으로 인해 표면에 공공형성이 많아졌으며 이러한 결함자리에 상부전극이 침투함으로 누설전류 특성이 저하되 는 것으로 생각된다.[7] 한편 $750\left[{ }^{\circ} \mathrm{C}\right]$ 에서 열처리한 $\mathrm{SBN}$ 박 막의 누설전류 밀도는 $6.28 \times 10^{-5}\left[\mathrm{~A} / \mathrm{cm}^{2}\right]$ 를 나타내었다.

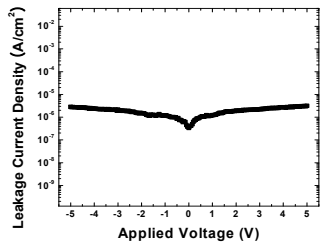

(a) $600\left[{ }^{\circ} \mathrm{C}\right]$

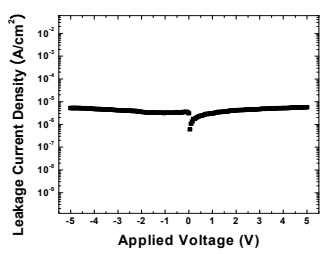

(c) $700\left[{ }^{\circ} \mathrm{C}\right]$

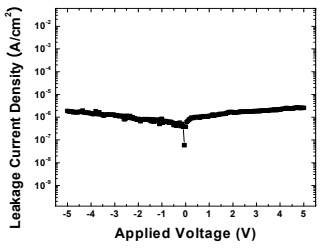

(b) $650\left[{ }^{\circ} \mathrm{C}\right]$

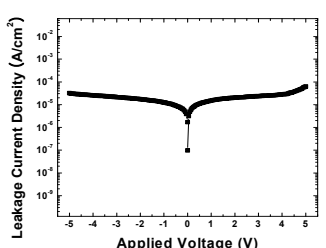

(d) $750\left[{ }^{\circ} \mathrm{C}\right]$

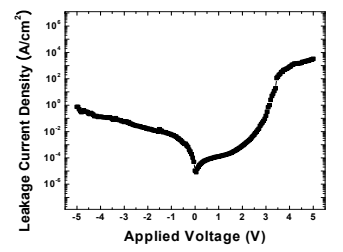

(e) $800\left[{ }^{\circ} \mathrm{C}\right]$

그림 2 열처리온도에 따른 SBN 박막의 I-V 특성

Fig. $2 \quad-V$ characteristics of SBN thin film with annealing temperature

그림 3은 열처리된 $\mathrm{SBN}$ 박막에 5[V] bipolar 펄스를 인 가하였을 때 Fatigue cycles에 따른 분극량의 변화를 나타낸 것이다. 그림에서 알 수 있는 것처럼 모든 박막에 $10^{8}$ switching cycles을 반복 인가한 후에도 분극량의 변화는 거 의 없었서 본 연구에서 얻어진 $\mathrm{SBN}$ 박막이 우수한 피로특 성을 나타내고 있음을 알 수 있었다. 일반적으로 피로특성 은 박막 내에 존재하는 산소 공공에 의해 공간전하가 형성 
되거나 또는 박막내에 외부 전기장의 방향을 바꾸어 주었을 때 분극이 반전되지 않는 비반전층에 의해 발생된다고 보고 되고 있다.[7, 8] 또한 열처리온도가 증가함에 따라 분극율이 약간씩 커지는 경향을 나타내고 있는데 이러한 잔류분극의 증가는 누설전류의 증가를 원인으로 생각할 수 있다.

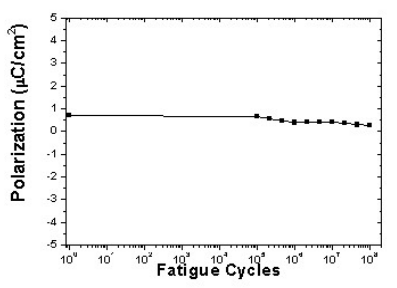

(a) $600\left[{ }^{\circ} \mathrm{C}\right]$

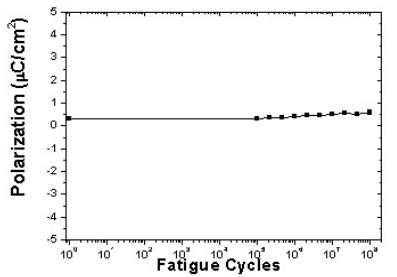

(c) $700\left[{ }^{\circ} \mathrm{C}\right]$

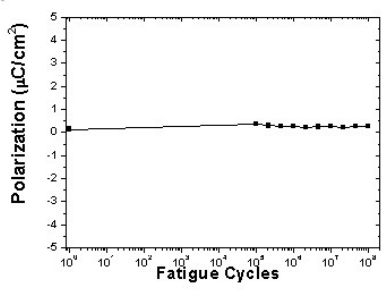

(b) $650\left[{ }^{\circ} \mathrm{C}\right]$

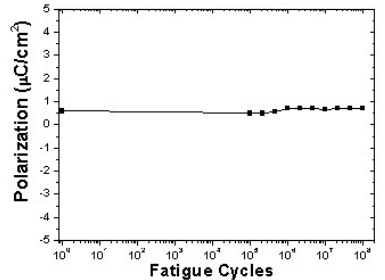

(d) $750\left[{ }^{\circ} \mathrm{C}\right]$

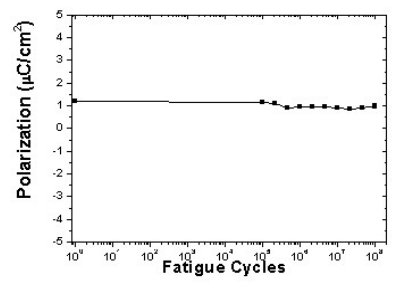

(e) $800\left[{ }^{\circ} \mathrm{C}\right]$

그림 3 열처리온도에 따른 SBN 박막의 피로특성

Fig. 3 Fatigue characteristics of SBN thin film with annealing temperature

\section{4. 결 론}

$\mathrm{RF}$ 마그네트론 스퍼터링법으로 제작된 $\mathrm{SBN}$ 세라믹 박막 의 열처리온도 따른 분극특성을 측정한 결과는 다음과 같다. 모든 박막에서 거의 선형적인 $\mathrm{P}-\mathrm{V}$ 특성을 나타내었고, $800\left[{ }^{\circ} \mathrm{C}\right]$ 에서 열처리한 $\mathrm{SBN}$ 박막의 잔류분극 값 및 항전압 은 각각 $0.6\left[\mu \mathrm{C} / \mathrm{cm}^{2}\right], 1.2[\mathrm{~V}]$ 를 얻을 수 있었다. 열처리온도 따른 박막의 누설전류 밀도는 열처리온도 $600\left[{ }^{\circ} \mathrm{C}\right]$ 에서 650 $\left[{ }^{\circ} \mathrm{C}\right]$ 증가할 때는 $3.15 \times 10^{-6}\left[\mathrm{~A} / \mathrm{cm}^{2}\right]$ 에서 $2.57 \times 10^{-6}\left[\mathrm{~A} / \mathrm{cm}^{2}\right]$ 으로 약간 향상되었지만 열처리온도 $700\left[{ }^{\circ} \mathrm{C}\right]$ 이상에서는 더 나빠 지다가 $800\left[{ }^{\circ} \mathrm{C}\right]$ 에서는 절연 파괴되는 것을 확인할 수 있었 다. 한편 $750\left[{ }^{\circ} \mathrm{C}\right]$ 에서 열처리한 $\mathrm{SBN}$ 박막의 누설전류 밀도 는 $2.57 \times 10^{-6}\left[\mathrm{~A} / \mathrm{cm}^{2}\right]$ 를 나타내었다. 또한 $\mathrm{SBN}$ 박막의 Fatigue cycles에 따른 분극량의 변화는 모든 박막에 $10^{8}$ switching cycles을 반복 인가한 후에도 분극량의 변화는 거 의 없는 우수한 피로특성을 나타내고 있음을 알 수 있었다.

\section{참 고 문 헌}

[1] Keisuke Saito, Masatoshi Mitsuya, Norimasa Nukaga, Isao Yamaji, Takao Akai and Hiroshi Funakubo, "Method of Distinguishing $\mathrm{SrBi}_{2} \mathrm{Ta}_{2} \mathrm{O}_{9}$ Phase from Fluorite Phase Using X-Ray Diffraction Reciprocal Space Mapping", Jpn. J. Appl. Phys. Vol. 39 Pt.1, No. 9B, pp. 5489-5495, 2000.

[2] C Bedoya, Ch Muller, F Jacob, Y Gagou, M-A Fremy and E Elkaim "Magnetic- field-induced orientation in $\mathrm{Co}_{-}$doped $\mathrm{SrBi}_{2} \mathrm{Ta}_{2} \mathrm{O}_{9}$ ferroelectric oxide" J. Phys.: Condens. Matter 14, No. 45 pp. 11849-11857, 2002.

[3] Jin-Sa Kim and Chung-Hyeok Kim "Surface Morphology and Dielectric Properties of SBN Thin Film by RF Sputtering Method", J. of KIEEME, Vol. 22, No. 8 pp. 671-672, 2009.

[4] Jin-Sa Kim "Properties of Annealing Temperature of Ceramic Thin Film by RF Sputtering Method" Trans. KIEE, Vol. 58p, No. 4 pp. 538-540, 2009.

[5] Nak-jin Seong and Soon-Gil Yoon "Preparation and Characteristics of Ferroelectric $\mathrm{SrBi}_{2} \mathrm{Ta}_{2} \mathrm{O}_{9}$ Thin Films Deposited by Plasma-Enhanced Metalorganic Chemical Vapor Depotion Technique with Various Depotion Temperature", Korean Journal of Materials Research, Vol. 7, No. 5 pp. 381-385, 1997.

[6] Dong Hoon Kang, Hoon Sang Choi "Growth and Characteristics of $\mathrm{SrBi}_{2} \mathrm{Nb}_{2} \mathrm{O}_{9}$ Thin Films for Memory Devices", Korean Journal of Materials Research, Vol. 12, No. 6 pp. 464-469, 2002.

[7] Jin-Sa Kim " Electrical Properties with Annealing Temperature of SBN Thin Film" Trans. KIEE, Vol. 59, No. 6 pp. 1083-1086, 2010.

[8] Seung-Chang Shin, Moon-Kee Lee et al, "Electric Properties of BST Thin with $\mathrm{Ar} / \mathrm{O} 2$ ratio", J. of KIEEME, Vol. 12, No. 5 pp. 437-439, 1999.
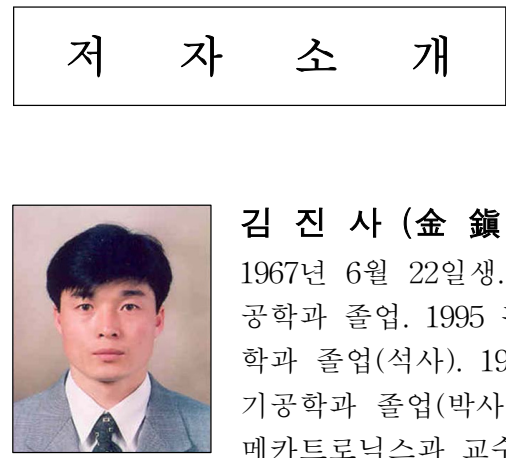

김 진 사 (金 鎭 士)

1967년 6월 22일생. 1993년 원광대 전기 공학과 졸업. 1995 광운대 대학원 전기공 학과 졸업(석사). 1998 광운대 대학원 전 기공학과 졸업(박사). 현재 조선이공대학 메카트로닉스과 교수

Tel : 062-230-8292

Fax : 062-230-8291

E-mail : kimjs@chosun-c.ac.kr 